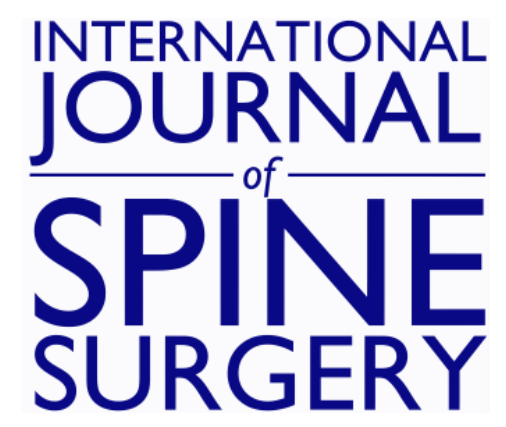

\title{
Treatment of Symptomatic Lumbar Disc Degeneration with the VariLift-L Interbody Fusion System: Retrospective Review of 470 Cases
}

Warren F. Neely, Frank Fichtel, Diana Cardenas del Monaco and Jon E. Block

Int J Spine Surg 2016, 10 ()

doi: https://doi.org/10.14444/3015

http://ijssurgery.com/content/10/15

This information is current as of April 26, 2023.

Email Alerts Receive free email-alerts when new articles cite this article. Sign up at:

http://ijssurgery.com/alerts

The International Journal of Sping Surgenthttp://ijssurgery.com/ by guest on April 26, 2 2397 Waterbury Circle, Suite 1,

Aurora, IL 60504, Phone: +1-630-375-1432

(C) 2016 ISASS. All Rights Reserved. 


\section{Treatment of Symptomatic Lumbar Disc Degeneration with the VariLift-L Interbody Fusion System: Retrospective Review of 470 Cases}

Warren F. Neely, MD, ${ }^{1}$ Frank Fichtel, MD, ${ }^{1}$ Diana Cardenas del Monaco, PhD, 2 Jon E. Block, PhD 3

${ }^{1}$ Kingman, Neely, \& Fichtel MDs, San Antonio, TX, ${ }^{2}$ Texas Neurosciences Institute, San Antonio, TX, 3'Jon Block, PhD, San Francisco, CA

\section{Abstract}

Background

Many first generation stand-alone fusion cages required endplate decortication and surgical impaction during the procedure resulting in segmental subsidence, implant migration and loss of lordosis postoperatively. The primary objective of this study was to evaluate radiographically, in a large series of patients, whether engineering and design modifications incorporated in a specific stand-alone, expandable interbody fusion device (VariLift ${ }^{\circledR}-\mathrm{L}$ ) adequately addressed previously recognized deficiencies of stand-alone interbody cages.

\section{Methods}

In this retrospective chart review of 470 patients (642 treated levels), we evaluated radiographic evidence of fusion, subsidence and migration following a one- or two-level PLIF procedure utilizing this stand-alone expandable interbody fusion device. A secondary objective was to corroborate the low morbidity and symptomatic improvements achieved with previous interbody cage devices used to treat symptomatic disc degeneration.

Results

The average postoperative followup was $3.9 \pm 1.8$ years and a solid fusion rate of $94 \%$ was achieved among patients with $\geq 9$ months of radiographic followup. Subsidence $>3 \mathrm{~mm}$ was noted at 10 levels with no cases of device migration. Composite back pain severity scores improved from $8.5 \pm 1.5$ preoperatively to $0.8 \pm 1.5$ at final followup $(\mathrm{p}<0.001)$ and $94 \%$ of patients met or exceeded the minimal clinical important difference of 3.8 points. Eighteen patients required reoperation following the index procedure; 16 of these patients were treated for adjacent segment disease.

\section{Conclusions (LOE)}

The VariLift-L device has excellent clinical and technical performance characteristics, providing adequate stabilization of the anterior column without the need for supplemental posterior instrumentation. Level of Evidence IV. IRB Approval: Expedited Federal Register Categories 5\& 7: Methodist IRB 3/30/2011; Informed Consent statement: retrospective data collection, patients signed consent forms allowing for data to be used for research.

\section{Clinical Relevance}

This stand-alone expandable fusion device produced high fusion rates, a low incidence of reoperation and effective symptom relief in a "real world" setting among a large group of patients with refractory symptomatic disc degeneration.

KEYWORDS: SPINAL FUSION, CAGES, INTERBODY, DEGENERATIVE DISC DISEASE, EXPANDABLE STAND-ALONE DEVICE

VOLUME 10 ARTICLE 15 DOI: 10.14444/3015

\section{Introduction}

Fusion of the anterior spinal column is a widely accepted and frequently utilized surgical procedure for treatment of instability related to symptomatic disc degeneration refractory to conservative care. To pro- vide a consistent and reproducible surgical procedure, interbody fusion cages were developed to stabilize the anterior segment while bony ingrowth from vertebrae to the bone graft occurred. ${ }^{1}$ These devices also have the advantage of preserving intervertebral and foraminal height that can be lost when using 
bone graft material alone.

Most of the first generation stand-alone fusion cages required endplate decortication and surgical impaction during the procedure that has been implicated in segmental subsidence, implant migration and loss of lordosis occurring postoperatively. ${ }^{2-4}$ Historically, to offset these shortcomings, supplemental posterior fixation with pedicle screws and rods has been employed to ensure biomechanical stability. However, supplemental fixation methods are more technically demanding and increase operative time, blood loss and complications such as nerve root injury and violation of the adjacent facet joints. ${ }^{5,6}$ This method of instrumented fusion may also be associated with an increased risk of symptomatic adjacent segment disease. ${ }^{7}$

The VariLift ${ }^{\circledR}$-L interbody fusion system was developed as a stand-alone expandable fusion device that does not require supplemental fixation. It draws upon the established benefits of previous interbody cage designs and, more importantly, addresses known shortcomings of early designs by providing immediate segmental stability at the time of implantation, maintenance of natural lordosis and resistance to subsidence and migration without using supplemental screws or plating. The large chamber and wide fenestrations allow for the use of substantial bone graft volume and improved radiographic visualization of fusion progression. This low profile device is implanted without impaction or decortication of the endplates, and expanded in situ to offer solid purchase to the endplates over a large contact area.

\section{Materials and Methods}

The primary objective of this retrospective chart review was to evaluate radiographically, in a large series of patients, whether engineering and design modifications incorporated in a specific stand-alone, expandable interbody fusion device (VariLift-L, Wenzel Spine, Austin, TX, USA) adequately addressed previously recognized deficiencies of stand-alone interbody cages. A secondary objective was to corroborate the well-documented low perioperative morbidity, clinical benefits and reoperation rates associated with posterior lumbar interbody fusion (PLIF).
All patients included in this review were surgically treated between August 2003 and October 2009 by two surgeons (WN, FF) at the same institution in San Antonio, TX. Eligibility required one year of postoperative followup. Exclusion criteria included, 1) surgical treatment at more than 2 levels, 2) greater than Grade I spondylolisthesis, or 3) treatment for adjacent segment disease. Institutional review board approval was obtained to conduct this chart review.

The design characteristics, indications for use, operative technique and preliminary clinical experience with the VariLift device have been published previously. ${ }^{8}$ The VariLift-L is a titanium expandable, stand-alone interbody fusion device (Figure 1). Prior to surgical implantation, the device is cylindrical in shape with self-tapping threads, allowing for advancement into the intervertebral space without impaction. The device is then expanded in situ by advancing a sliding expansion plate to lock and secure the device in proper anatomical position (Figure 2). The unique in situ expansion provides immediate fixation and purchase to the preserved endplates. The bone graft chamber and fenestrations on all four sides of the implant allow for bone graft contact with the endplates to promote intervertebral bony fusion.

Figure 3 shows sequential intraoperative fluoroscopic images of the operative steps involved in a single level bilateral cage implantation procedure. Briefly, all surgeries used a standard PLIF procedure via a minimally invasive posterior midline approach. Bilateral decompression was performed and disc tissue ex-

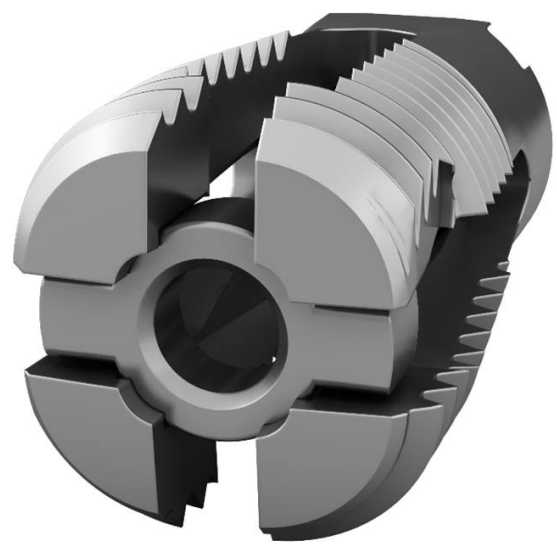

Fig. 1. VariLift-L expandable stand-alone lumbar interbody fusion device. 
cised. In removing disc and cartilaginous tissue, care was taken to preserve the integrity of the endplates without concomitant decortication. Under fluoroscopic guidance, the disc space was distracted with a temporary spacer, the implants were sized, and then inserted, positioned and expanded bilaterally in the disc space. Finally, after flushing with an antibiotic solution, locally acquired bone graft was packed into the device, followed by standard surgical closure.

Anteroposterior, lateral and dynamic flexion/extension radiographs were evaluated postoperatively for evidence of progressing or solid bony fusion at the index level(s) by the operating surgeon. A solid fusion was defined radiographically as presence of visible bone within the cage device, the absence of radiolucent halo effects around the implant, and the absence of gross motion on dynamic films.

Subsidence was defined as displacement of the device into the caudal vertebral body greater than $3 \mathrm{~mm}$ by comparing late postoperative $\mathrm{x}$-rays ( $\geq 9$ months) with those taken immediately postoperatively. ${ }^{3}$ The

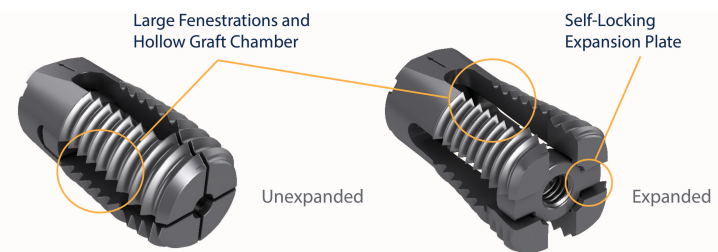

Fig. 2. Expansion of the VariLift-L device providing maintenance of segmental lordosis due to the wedge shape of the deployed implant. The large hollow inner chamber and wide fenestrations allow easy placement of bone graft and improved radiographic visualization to assess fusion status.

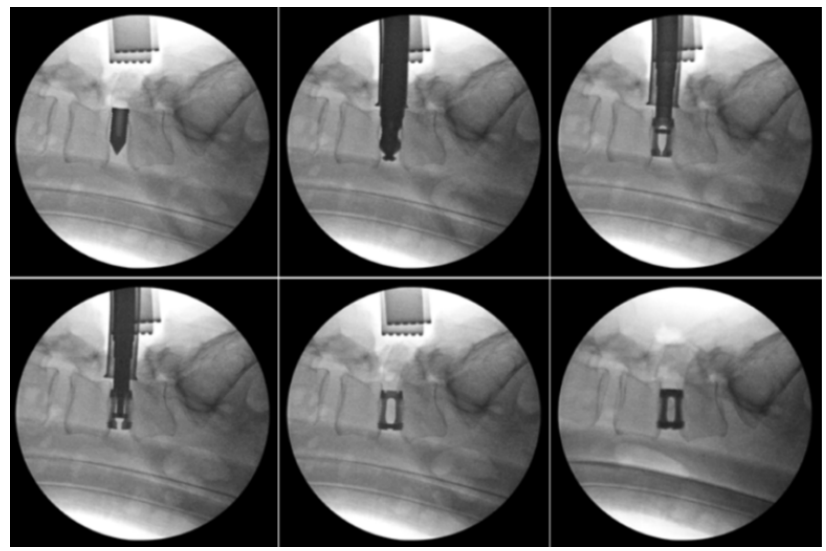

Fig. 3. Fluoroscopic evaluation of intraoperative surgical technique; A) disc distraction with temporary interbody spacer, B) sizing of the VariLift-L, C) device insertion, D) intermediate device expansion, E) full device expansion, F) final fluoroscopic image of expanded bilateral devices. degree of subsidence was calculated by drawing two lines to demarcate the cephalad and caudal endplates and measuring the distance between the midpoints of these two lines in millimeters.

Using the same set of radiographs, migration of the device in the intervertebral space was determined by calculating the distance from the posterior edge of the implant compared with the posterior edge of the caudal vertebra. Migration was defined as movement greater than $3 \mathrm{~mm}^{2}$

Back pain severity scores were assigned to each patient on an 11-point numeric scale at each clinical followup visit. Pain scores consisted of a composite assessment of patient self-reported symptoms, extent of pain medication usage, clinical signs upon physical examination and surgeon chart notations. A patient was consider a clinical success if their minimal clinically important improvement in pain score between baseline and final followup was $\geq 3.8$ points. ${ }^{9}$

\section{Results}

Four hundred and seventy (470) patients with symptomatic disc degeneration who had exhausted conservative care were treated with PLIF using the VariLift-L expandable fusion device. The mean age was 57.6 years (range: 19-86 years) and the average postoperative followup was $3.9 \pm 1.8$ years with 163 patients (35\%) achieving 5 years of followup. Background characteristics of this study group are detailed in Table 1. Two devices were implanted bilaterally per level in all patients and approximately $37 \%$ $(\mathrm{n}=172)$ were treated at two contiguous levels (Table 2). Overall, 642 levels were treated with L4-5 accounting for nearly half of all implanted levels.

Perioperatively, blood loss averaged $353 \pm 231 \mathrm{cc}$. Forty-two patients (9\%) exhibited blood loss in excess of $750 \mathrm{cc}$ with $74 \%(\mathrm{n}=31)$ of these patients undergoing two level procedures. Additionally, thirty-one patients $(6.7 \%)$ demonstrated an unresolved or new onset neurological sequela in the form of a motor deficit postoperatively (Table 3 ).

The solid fusion rate was $94 \%$ (263 of 281) among patients with $\geq 9$ months of radiographic followup. At 6 
months, an additional 62 of 68 available patients showed radiographic evidence of progression toward fusion. Overall, 93\% (325 of 349) of patients showed

Table 1. Patient Baseline Characteristics.

\begin{tabular}{|c|c|}
\hline Characteristic & Value $(N=470)$ \\
\hline \multicolumn{2}{|l|}{ Sex, n (\%) } \\
\hline Female & $261(55.5)$ \\
\hline \multicolumn{2}{|l|}{ Demographic Information, n (\%) } \\
\hline History Of Smoking* & $119(25.5)$ \\
\hline Employed ${ }^{\dagger}$ & $352(77.7)$ \\
\hline Spine Surgical History* & $134(29.8)$ \\
\hline \multicolumn{2}{|l|}{ Pre-Existing Conditions, n (\%) } \\
\hline Diabetes & $51(10.9)$ \\
\hline Osteoporosis & $21(4.5)$ \\
\hline Obesity & $27(5.7)$ \\
\hline HTN & $132(28.1)$ \\
\hline Cardio HX & $49(10.4)$ \\
\hline Hypercholestermia & $60(12.8)$ \\
\hline Cancer HX & $34(7.2)$ \\
\hline Thyroid Disorders & $33(7.0)$ \\
\hline \multicolumn{2}{|l|}{ Pre-surgical Symptoms, n (\%) } \\
\hline Back Pain $§$ & $467(99.6)$ \\
\hline Radicular Pain $\$$ & $434(92.6)$ \\
\hline Bowel/Bladder Dysfunction* & $9(2.0)$ \\
\hline \multicolumn{2}{|l|}{ Diagnosis, n (\%) } \\
\hline Spondylosis & $335(71.9)$ \\
\hline Spondylolisthesis (Grade 1 or less) & $78(16.6)$ \\
\hline Herniated Nucleus Pulposis ${ }^{\#}$ & $412(89.0)$ \\
\hline Facet Joint Degeneration ${ }^{* *}$ & $397(87.1)$ \\
\hline Instability & $462(98.7)$ \\
\hline Osteophyte Formation ${ }^{* *}$ & $376(82.5)$ \\
\hline Decreased Disc Height\# & $452(97.6)$ \\
\hline
\end{tabular}

Table 2. Operative Levels.

\begin{tabular}{|l|r|}
\hline Variable & \\
\hline Number of Levels Implanted Per Patient & Value (N = 470) \\
\hline 1 Level & $298(63.4)$ \\
2 Level & $172(36.6)$ \\
\hline Total Levels Implanted & Value (N = 642) \\
\hline L1-2 & $1(0.2)$ \\
L2-3 & $27(4.1)$ \\
L3-4 & $114(17.5)$ \\
L4-5 & $319(48.9)$ \\
L5-S1 & $181(27.7)$ \\
\hline
\end{tabular}

either progression toward or solid fusion at the index level(s) (Figure 4).

Paired early and late postoperative radiographs were available for 326 patients (69\%) representing 445 levels $(69 \%)$. Subsidence $>3 \mathrm{~mm}$ was noted at 10 levels (2\%). Two of these patients subsequently were treated at an adjacent level using the VariLift-L device. However, all patients exhibiting radiographic evi-

Table 3. Intra-operative and Post-operative Complications.
\begin{tabular}{|l|r|}
\hline Complication & Value $(\mathbf{N}=\mathbf{4 7 0})$ \\
\hline Excessive Blood Loss $(>750 \mathrm{cc})$ & $42(8.9)$ \\
\hline Dural Laceration & $2(<1.0)$ \\
\hline Superficial Wound Infection & $12(2.6)$ \\
\hline CSF Leak & $11(2.4)$ \\
\hline Post-Operative Radiculopathy & $18(3.9)$ \\
\hline Sensory Deficit & $22(4.7)$ \\
\hline Motor Deficit & $31(6.7)$ \\
\hline
\end{tabular}

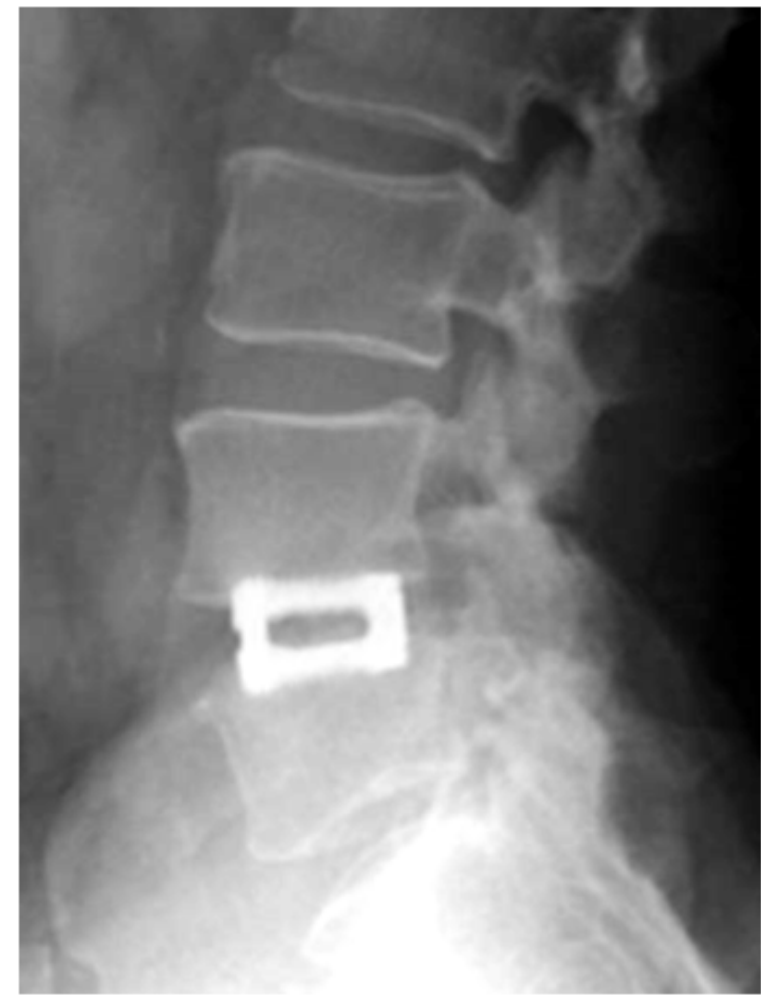

Fig. 4. Twelve month postoperative lateral radiographic image of bilaterally implanted devices, maintaining excellent anatomical position at L4-5 and purchase to the endplates. The large fenestrations allow exquisite radiographic visualization of progression of bony fusion within the cage chamber. 
dence of subsidence were asymptomatic at the index operative level. No patient exhibited device migration $>3 \mathrm{~mm}$ at any analyzed level.

Composite back pain severity scores improved from $8.5 \pm 1.5$ preoperatively to $0.8 \pm 1.5$ at final followup $(\mathrm{p}<0.001)$ (Figure 5). Additionally, of the $352 \mathrm{pa}-$ tients with pain assessments at $\geq 9$ months, 334 (94\%) met or exceeded the minimal clinical important difference of 3.8 points.

There were eighteen patients (4\%) that required reoperation following the index procedure; $16(89 \%)$ of these patients were treated for adjacent segment disease. Of the two patients that required reoperation at the index level, one developed worsening symptoms following a fall and the other suffered a deep wound infection.

\section{Discussion}

This retrospective review of a large series of cases suggests excellent technical and clinical performance of a novel, stand-alone expandable interbody fusion device for the treatment of symptomatic disc degeneration and corroborates previous studies of standalone cages. ${ }^{10}$ The standard PLIF procedure provides satisfactory nerve root decompression, axial loading of the anterior column, immediate restoration of disc height and foraminal patency, and compressive loading of the interbody bone graft. However, utilization of first generation stand-alone interbody cages exposed a number of deficiencies including subsidence, migration and difficulty assessing bony fusion, partic-

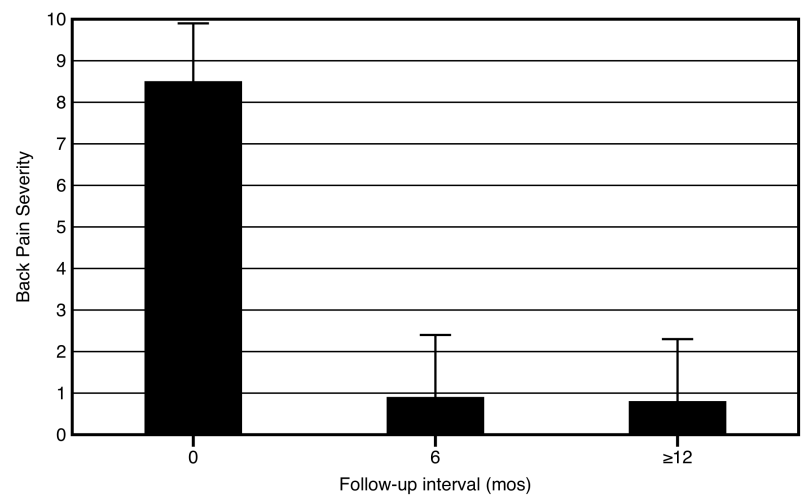

Fig. 5. Composite back pain severity scores preoperatively $(n=470)$ as well as at 6 months $(n=419,89 \%)$ and 12 months $(n=352,75 \%)$. ularly when using cylindrical cages that do not preserve the cortical vertebral endplates. ${ }^{11}$

Preservation of disk height and lumbar lordosis postoperatively is integral to long-term maintenance of clinical benefit. ${ }^{12,13}$ Subsidence of an interbody device can cause narrowing of the neural foramina leading to new onset pain and dysfunction. ${ }^{2}$ Preventing device subsidence is vital and depends, in large part, on adequate preservation of the cortical endplates. ${ }^{3}$ Indeed, removal of the endplate has been shown to reduce the strength and stiffness of the vertebral construct, facilitating subsidence. ${ }^{14}$ Facet resection can likewise have a destabilizing effect on stand-alone interbody fusion devices. ${ }^{4}$ The minimal impact surgical procedure used to implant the low-profile VariLift-L device preserves both the endplates and the posterior anatomy, thereby minimizing subsidence, migration and instability. We found a low incidence of subsidence $(2 \%)$ and no instances of migration in this case series that may be attributable to these operative techniques and the unique design characteristics of this device such as the ability to expand in situ to provide immediate fixation.

The expandable feature of the VariLift-L converts the low-profile cylindrical implant to a wedge shaped implant when fully deployed to support preservation of lumbar lordosis. Previous reports have established the importance of restoring and maintaining lordosis with stand-alone cage technologies. ${ }^{15-17}$ Additionally, with the PLIF procedure, two bilateral devices are implanted, providing maximal endplate contact which has been shown to be preferable. ${ }^{12,18}$ When expanded, the large open fenestrations also allow for excellent radiographic visualization. ${ }^{13}$

We noted substantial symptom amelioration with the PLIF procedure utilizing the VariLift-L device with over $90 \%$ of the patients meeting or exceeding the minimal clinically important difference in pain scores at final followup. Previous systematic reviews of spinal fusion for treatment of degenerative disc disease have also confirmed postoperative pain relief. ${ }^{19,20}$ However, the approximately $91 \%$ improvement in back pain severity over baseline in the current study is substantially greater than the median $57 \%$ improvement for PLIF estimated across a large number of 
studies. ${ }^{19}$ This difference is likely due to the varying methods used to assess pain severity including the "composite" score used in the current study as well as the previously described enhanced treatment effects noted in retrospective studies compared to randomized controlled trials. ${ }^{19}$

This retrospective observational study has several limitations. First, long-term radiographic fusion evaluation at 2 years was limited as patients were not required to return for radiographic followup if they experienced clinically significant symptom amelioration. Second, because a conventional pain severity measurement such as a visual analog scale was not used, we were constrained to extrapolate a composite pain score from the patient charts. Third, this study lacked a standardized measure of back function such as the Oswestry Disability Index. Future assessment of this device should ideally include these outcome instruments.

In conclusion, this retrospective chart review found the VariLift-L device to have excellent technical performance characteristics, providing adequate stabilization of the anterior column without the need for supplemental posterior instrumentation. This standalone expandable device produced high fusion rates, a low incidence of reoperation and effective symptom relief in a large group of patients.

\section{Acknowledgments}

The authors thank Terry Meredith for graphical assistance.

\section{References}

1. Blumenthal SL, Ohnmeiss DD, Nass. Intervertebral cages for degenerative spinal diseases. Spine J. Jul-Aug 2003;3(4):301-309.

2. Chen L, Yang H, Tang T. Cage migration in spondylolisthesis treated with posterior lumbar interbody fusion using BAK cages. Spine (Phila Pa 1976). Oct 1 2005;30(19):2171-2175.

3. Choi JY, Sung KH. Subsidence after anterior lumbar interbody fusion using paired stand-alone rectangular cages. Eur. Spine J. Jan 2006;15(1):16-22.
4. Zdeblick TA, Phillips FM. Interbody cage devices. Spine (Phila Pa 1976). Aug 1 2003;28(15 Sup$\mathrm{pl):S2-7.}$

5. Babu R, Park JG, Mehta AI, et al. Comparison of superior-level facet joint violations during open and percutaneous pedicle screw placement. Neurosurgery. Nov 2012;71(5):962-970.

6. Patel RD, Graziano GP, Vanderhave KL, Patel AA, Gerling MC. Facet violation with the placement of percutaneous pedicle screws. Spine (Phila $\mathrm{Pa}$ 1976). Dec 15 2011;36(26):E1749-1752.

7. Lee CS, Hwang CJ, Lee SW, et al. Risk factors for adjacent segment disease after lumbar fusion. Eur. Spine J. Nov 2009;18(11):1637-1643.

8. Emstad E, Del Monaco DC, Fielding LC, Block JE. The VariLift((R)) Interbody Fusion System: expandable, standalone interbody fusion. Med Devices (Auckl). 2015;8:219-230.

9. Parker SL, Mendenhall SK, Shau D, et al. Determination of minimum clinically important difference in pain, disability, and quality of life after extension of fusion for adjacent-segment disease. J. Neurosurg. Spine. Jan 2012;16(1):61-67.

10. Lequin MB, Verbaan D, Bouma GJ. Posterior lumbar interbody fusion with stand-alone Trabecular Metal cages for repeatedly recurrent lumbar disc herniation and back pain. J. Neurosurg. Spine. Jun 2014;20(6):617-622.

11. Polikeit A, Ferguson SJ, Nolte LP, Orr TE. The importance of the endplate for interbody cages in the lumbar spine. Eur. Spine J. Dec 2003;12(6):556-561.

12. Marchi L, Abdala N, Oliveira L, Amaral R, Coutinho E, Pimenta L. Radiographic and clinical evaluation of cage subsidence after stand-alone lateral interbody fusion. J. Neurosurg. Spine. Jul 2013;19(1):110-118.

13. Schiffman M, Brau SA, Henderson R, Gimmestad G. Bilateral implantation of low-profile interbody fusion cages: subsidence, lordosis, and fusion analysis. Spine J. Sep-Oct 2003;3(5):377-387.

14. Oxland TR, Grant JP, Dvorak MF, Fisher CG. Effects of endplate removal on the structural properties of the lower lumbar vertebral bodies. Spine (Phila Pa 1976). Apr 15 2003;28(8):771-777.

15. Barrey C, Darnis A. Current strategies for the restoration of adequate lordosis during lumbar fusion. World J Orthop. Jan 18 2015;6(1):117-126. 
16. Kim JT, Shin MH, Lee HJ, Choi DY. Restoration of lumbopelvic sagittal alignment and its maintenance following transforaminal lumbar interbody fusion (TLIF): comparison between straight type versus curvilinear type cage. Eur. Spine J. Mar 252015. 17. Godde S, Fritsch E, Dienst M, Kohn D. Influence of cage geometry on sagittal alignment in instrumented posterior lumbar interbody fusion. Spine (Phila Pa 1976). Aug 1 2003;28(15):1693-1699.

18. Zhang JD, Poffyn B, Sys G, Uyttendaele D. Are stand-alone cages sufficient for anterior lumbar interbody fusion? Orthop. Surg. Feb 2012;4(1):11-14.

19. Andersson GB, Mekhail NA, Block JE. Treatment of intractable discogenic low back pain. A systematic review of spinal fusion and intradiscal electrothermal therapy (IDET). Pain Physician. Jul 2006;9(3):237-248.

20. Geisler FH, Blumenthal SL, Guyer RD, et al. Neurological complications of lumbar artificial disc replacement and comparison of clinical results with those related to lumbar arthrodesis in the literature: results of a multicenter, prospective, randomized investigational device exemption study of Charite intervertebral disc. Invited submission from the Joint
Section Meeting on Disorders of the Spine and Peripheral Nerves, March 2004. J. Neurosurg. Spine. Sep 2004;1(2):143-154.

\section{Disclosures \& COI}

Block reports personal fees from Wenzel Spine during the conduct of the study; Del Monaco, at the time of data collection, was a paid research consultant for Wenzel Spine and at the time of publication is a full-time employee of Wenzel Spine; Neely reports serving on the Scientific/Medical Advisory Panel for Wenzel Spine pro bono;

\section{Corresponding Author}

Jon E. Block, Ph.D., 2210 Jackson Street, Ste. 401, San Francisco, CA 94115. jb@drjonblock.com.

Published 3 May 2016.

This manuscript is generously published free of charge by ISASS, the International Society for the Advancement of Spine Surgery. Copyright @ 2016 ISASS. To see more or order reprints or permissions, see http://ijssurgery.com. 